\title{
Arterial blood gas and acid-base balance in patients with pregnancy-induced hypertension syndrome
}

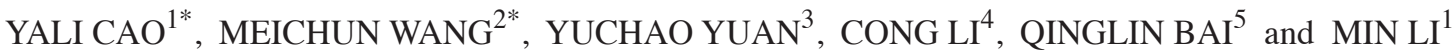 \\ ${ }^{1}$ Department of Obstetrics, The First People's Hospital of Jining, Jining, Shandong 272011; \\ ${ }^{2}$ Department of Clinical Laboratory, Yantaishan Hospital of Yantai, Yantai, Shandong 264025; Departments of \\ ${ }^{3}$ Ultrasound, ${ }^{4}$ Otolaryngology and ${ }^{5}$ Operating Room, People's Hospital of Zhangqiu District, \\ Jinan, Shandong 250000, P.R. China
}

Received April 16, 2018; Accepted October 11, 2018

DOI: $10.3892 / \mathrm{etm} .2018 .6893$

\begin{abstract}
This study aimed to investigate the expression of arterial blood gas and acid-base balance in patients with pregnancy-induced hypertension syndrome and their influence on newborns. A total of 348 patients with pregnancy-induced hypertension syndrome (research group) admitted and treated in the First People's Hospital of Jining from March 2013 to March 2016 were retrospectively analyzed, and another 156 cases of healthy pregnant women who were physically examined were selected as the control group. Blood gas analysis was performed on pregnant women, and $\mathrm{pH}$ value, partial pressure of oxygen $\left(\mathrm{PO}_{2}\right)$, partial pressure of carbon dioxide $\left(\mathrm{PCO}_{2}\right)$, bicarbonate radical $\left(\mathrm{HCO}_{3}{ }^{-}\right)$and base excess (BE) were included as test indexes. Apgar score was made for newborns for neonatal asphyxia. The evaluation was performed at 1,5, and $10 \mathrm{~min}$ after birth to analyze the correlation between the maternal arterial blood $\mathrm{pH}$ and the neonatal Apgar score. The $\mathrm{pH}$ value, and $\mathrm{PO}_{2}$ and $\mathrm{HCO}_{3}{ }^{-}$levels in the research group were lower than those in the control group $(\mathrm{p}<0.05) . \mathrm{PCO}_{2}$ and $\mathrm{BE}$ levels in the research group were higher than those in the control group $(p<0.05)$. The incidence of neonatal mild asphyxia (Apgar score, 4-6 points) and neonatal severe asphyxia (Apgar score, $<4$ points) in the research group were higher than that in the control group $(\mathrm{p}<0.05)$. The Apgar score of newborns was positively correlated with the $\mathrm{pH}$ value of the arterial blood of pregnant women. Blood gas analysis in patients with pregnancy-induced hypertension syndrome is useful to a certain extent to evaluate the condition of the patient. The combination of the $\mathrm{pH}$ value of the patient and the
\end{abstract}

Correspondence to: $\mathrm{Dr}$ Min Li, Department of Obstetrics, The First People's Hospital of Jining, 6 Jiankang Road, Jining, Shandong 272011, P.R. China

E-mail:mww7p4@163.com

*Contributed equally

Key words: pregnancy-induced hypertension syndrome, blood gas analysis, acid-base balance, neonatal asphyxia, Apgar score
Apgar score of the newborns may help improve the judgement rate of neonatal asphyxia so as to improve the quality of childbirth by early monitoring and intervention of the newborns.

\section{Introduction}

Pregnancy-induced hypertension syndrome is a common disease of pregnant women during pregnancy, most of which occur after 20 weeks of pregnancy. Approximately $12 \%$ of maternal deaths in the Department of Obstetrics and Gynecology are related to pregnancy-induced hypertension. Edema and proteinuria occur in patients with milder conditions, while blurred vision and headaches occur in severe cases $(1,2)$. Without proper treatment, it may cause convulsions and coma in pregnant women. This not only damages the heart, liver, kidney function and coagulation system of pregnant women, but also adversely affects the placenta of the fetus and leads to the loss of placental function, thus, causing fetal growth retardation and fetal asphyxia death. The above is one of the main causes of death of pregnant women and perinatal infants (3). Pregnancy-induced hypertension syndrome may develop into eclampsia in severe cases, which may lead to changes in the fetus's internal environment of pregnant woman, seriously threatening the development and life of the fetus. Even if pregnant women are properly treated, the risk of high blood pressure, diabetes, and thrombotic diseases will be several times higher than that of normal individuals in the future, causing great harm (4). The clinical judgement of the newborn's physical condition is mainly based on the Apgar score, which can evaluate the newborn's respiration, heart rate, muscle tension, skin color and laryngeal reflex, and it is of great significance to the judgement of early neonatal asphyxia (5). With the advancement of medical technology, arterial blood gas analysis of pregnant women has also been gradually applied to the clinic. Blood gas analysis can reflect the lung respiratory function and acid-base balance of the body. According to relevant studies, pregnancy-induced hypertension syndrome can cause respiratory depression and acid-base imbalance in patients, and abnormal expression in arterial blood gas analysis results (6). The relationship between arterial blood gas and neonatal Apgar score in patients with pregnancy-induced hypertension syndrome is 
not yet clear. This study observed the expression of arterial blood gas indexes through arterial blood gas analysis in patients with pregnancy-induced hypertension syndrome, and it was analyzed combined with neonatal Apgar score, so as to provide a basis for the physical condition judgement, early guardianship and intervention of newborns.

\section{Materials and methods}

General clinical data. A total of 348 patients with pregnancy-induced hypertension syndrome treated in the Department of Obstetrics of the First People's Hospital of Jining (Jining, China) from March 2013 to March 2016 were retrospectively analyzed. All of the 348 patients, as research group, met the diagnostic criteria in the guidelines for the diagnosis and treatment of hypertensive disorder complicating pregnancy (2012) developed by the Chinese Society of Obstetrics and Gynecology (7). Another 156 healthy pregnant women were selected during the same period as the control group. The basic data of pregnant women are shown in Table I. Patients in the research group were graded and grouped according to the clinical diagnostic criteria of pregnancy-induced hypertension syndrome (8), among which there were 216 patients with mild pregnancy-induced hypertension (mild group), 73 patients with moderate pregnancy-induced hypertension (moderate group) and 59 patients with severe pregnancy-induced hypertension (severe group).

Inclusion and exclusion criteria. Inclusion criteria: patients with pregnancy-induced hypertension syndrome, maternal women with single fetus, pregnant women receiving arterial blood gas analysis and taking no uterotonic agents, and pregnant women without a history of intrauterine distress. Exclusion criteria: pregnant women with heart disease, heart failure, pulmonary heart disease, chronic nephritis, severe anemia, acute hemorrhage and trauma, hypoxic diseases (such as respiratory failure and poisoning), placenta previa, placental insufficiency, stillbirth, fetal malformation, huge fetus or intrauterine infection, or pregnant women whose neonates had jaundice. Apgar scoring (9) was conducted for the newborn, and all the patients involved in this study agreed and signed the informed consent. This study was approved by the Ethics Committee of the First People's Hospital of Jining.

Specimen collection and detection methods. In this study, arterial blood gas analysis was performed for all pregnant women. At 36 gestational weeks of pregnant women, $2 \mathrm{ml}$ whole blood was collected via radial artery puncture after disinfection. After extraction of blood, the artery was compressed using the sterile gauze for at least $5 \mathrm{~min}$. At the same time, the blood was blended evenly using the artery hemostix, and detected using the Roche Cobas b123 full-automatic blood gas analyzer (Shanghai Hanfei Medical Instrument Co., Ltd., Shanghai, China) and the detection kit (Beijing Puxi Technology Co., Ltd., Beijing, China). The detection indexes included $\mathrm{pH}$, partial pressure of oxygen $\left(\mathrm{PO}_{2}\right)$, partial pressure of carbon dioxide $\left(\mathrm{PCO}_{2}\right)$, bicarbonate radical $\left(\mathrm{HCO}_{3}^{-}\right)$and base excess $(\mathrm{BE})$, and they were detected in strict accordance with instructions of the blood gas analyzer and kit.
Table I. Clinical basic data of neonates in the research and control groups $[\mathrm{n}(\%)]$.

\begin{tabular}{lcccc}
\hline Items & $\begin{array}{c}\text { Research } \\
\text { group }\end{array}$ & $\begin{array}{c}\text { Control } \\
\text { group }\end{array}$ & $\chi^{2} / \mathrm{t}$ & P-value \\
\hline Age (years) & $26.46 \pm 5.17$ & $25.17 \pm 4.16$ & 3.208 & 0.326 \\
Birth experience & & & 1.526 & 0.247 \\
$\quad \begin{array}{l}\text { Primipara } \\
\text { Multipara }\end{array}$ & $216(62.07)$ & $96(61.54)$ & & \\
Delivery mode & $132(37.93)$ & $60(38.46)$ & & \\
Natural labor & $234(67.24)$ & $109(69.87)$ & & \\
Cesarean section & $114(32.76)$ & $47(30.13)$ & & \\
Place of residence & & & 2.930 & 0.304 \\
Urban area & $240(68.97)$ & $101(64.74)$ & & \\
Rural area & $108(31.03)$ & $55(35.26)$ & & \\
TP (g/l) & $58.36 \pm 5.78$ & $59.13 \pm 4.59$ & 0.845 & 0.089 \\
ALB (g/l) & $30.26 \pm 3.06$ & $29.83 \pm 4.17$ & 0.708 & 0.064 \\
Neonate's sex & & & 2.163 & 0.247 \\
Male & $196(56.32)$ & $73(46.79)$ & & \\
Female & $152(43.68)$ & $83(53.21)$ & & \\
Neonate's fetal & & & & \\
age (weeks) & $39.16 \pm 3.06$ & $38.45 \pm 2.46$ & 2.264 & 0.431 \\
Neonate's body & & & & \\
weight (g) & $3,315 \pm 436$ & $3,406 \pm 456$ & 3.681 & 0.201 \\
\hline
\end{tabular}

TP, total protein; ALB, albumin.

Apgar scoring criteria. Apgar scoring was performed for neonates at 1,5 and $10 \mathrm{~min}$ after maternal delivery. The neonate's breath, heart rate, muscular tension, skin color and stimulation reflex ability were observed. In this study, according to the Apgar scoring criteria reported by Iliodromiti et al (10), 7-10 points indicated normal neonates, 4-6 points indicated neonates with mild asphyxia, and $<4$ points indicated neonates with severe asphyxia.

Statistical analysis. Statistical Product and Service Solutions (SPSS) 16.0 software (Shanghai Cabit Information Technology Co., Ltd., Shanghai, China) was used for statistical analysis. Measurement data are presented as mean \pm standard deviation (mean $\pm \mathrm{SD}$ ), and t-test was used for the comparison of measurement data between the two groups. Chi-square test was used for enumeration data. Analysis of variance was used for the mean comparison among groups and Least Significant Difference test was the post hoc test. Logistic regression was adopted for correlation analysis. $\mathrm{P}<0.05$ suggested that the difference was statistically significant.

\section{Results}

Clinical data of research and control groups. There were no statistically significant differences in the comparison of maternal age, birth experience, delivery mode, place of residence, serum total protein (TP) and serum albumin (ALB) between the research and control groups 
Table II. Comparison of blood gas analysis results between the research and control groups (mean \pm SD).

\begin{tabular}{lcccrrr}
\hline & \multicolumn{3}{c}{ Research group } & & \\
\cline { 2 - 4 } Index & $\begin{array}{c}\text { Mild } \\
\text { group }(\mathrm{n}=216)\end{array}$ & $\begin{array}{c}\text { Moderate } \\
\text { group (n=73) }\end{array}$ & $\begin{array}{c}\text { Severe } \\
\text { group }(\mathrm{n}=59)\end{array}$ & $\begin{array}{c}\text { Control } \\
\text { group }(\mathrm{n}=156)\end{array}$ & $\mathrm{F}$ & P-value \\
\hline $\mathrm{pH}$ value & $7.29 \pm 0.12$ & $7.20 \pm 0.13$ & $7.09 \pm 0.29^{\mathrm{a}}$ & $7.37 \pm 0.07$ & 0.136 & 0.043 \\
$\mathrm{PO}_{2}(\mathrm{mmHg})$ & $64.16 \pm 6.26$ & $58.16 \pm 5.09$ & $54.73 \pm 4.76^{\mathrm{b}}$ & $68.16 \pm 6.84$ & 9.075 & 0.021 \\
$\mathrm{PCO}_{2}(\mathrm{mmol} / \mathrm{l})$ & $45.53 \pm 5.98$ & $50.26 \pm 6.74$ & $53.76 \pm 6.81^{\mathrm{c}}$ & $40.71 \pm 4.29$ & 6.284 & 0.026 \\
$\mathrm{HCO}_{3}^{-}(\mathrm{mmHg})$ & $23.16 \pm 3.59$ & $21.73 \pm 3.06$ & $19.78 \pm 2.46^{\mathrm{d}}$ & $26.16 \pm 4.16$ & 5.731 & 0.035 \\
$\mathrm{BE}(\mathrm{mmol} / \mathrm{l})$ & $3.16 \pm 2.53$ & $4.21 \pm 3.07$ & $4.97 \pm 3.58^{\mathrm{e}}$ & $2.98 \pm 2.49$ & 3.473 & 0.039
\end{tabular}

${ }^{a}$ The $\mathrm{pH}$ value in the severe group is lower than that in the mild group $(\mathrm{p}<0.05) .{ }^{\text {b }} \mathrm{PO}_{2}$ in the severe group is lower than that in the mild group $(\mathrm{p}<0.05) .{ }^{\mathrm{c}} \mathrm{PCO}_{2}$ in the severe group is higher than that in the mild group $(\mathrm{p}<0.05) .{ }^{\mathrm{d}} \mathrm{HCO}_{3}{ }^{-}$in the severe group is lower than that in the mild group $(\mathrm{p}<0.05)$. ${ }^{e} \mathrm{BE}$ in the severe group is higher than that in the mild group $(\mathrm{p}<0.05) . \mathrm{PO}_{2}$, partial pressure of oxygen; $\mathrm{PCO}_{2}$, partial pressure of carbon dioxide; $\mathrm{HCO}_{3}^{-}$, bicarbonate radical; $\mathrm{BE}$, base excess (BE).

Table III. Comparison of Apgar scores of neonates between the research and control groups [n (\%)].

\begin{tabular}{lcccccc}
\hline & \multicolumn{3}{c}{ Neonates in research group } & & \\
\cline { 2 - 4 } Apgar score & $\begin{array}{c}\text { Neonates in } \\
\text { mild group }(\mathrm{n}=216)\end{array}$ & $\begin{array}{c}\text { Neonates in } \\
\text { moderate group }(\mathrm{n}=73)\end{array}$ & $\begin{array}{c}\text { Neonates in } \\
\text { severe group }(\mathrm{n}=59)\end{array}$ & $\begin{array}{c}\text { Control } \\
\text { group }(\mathrm{n}=156)\end{array}$ & $\chi^{2}$ & P-value \\
\hline 7-10 points & $195(90.28)$ & $61(83.56)$ & $33(55.93)$ & $149(95.51)$ & 4.026 & 0.046 \\
4-6 points & $16(7.41)$ & $8(10.96)$ & $15(25.42)^{\mathrm{a}}$ & $7(4.49)$ & 4.267 & 0.039 \\
$<4$ points & $5(2.31)$ & $4(5.48)$ & $11(18.64)^{\mathrm{b}}$ & 0 & 5.317 & 0.035 \\
\hline
\end{tabular}

${ }^{a}$ The number of neonates with the Apgar score of 4-6 points in the severe group is larger than that in the mild group (p<0.05). ${ }^{b}$ The number of neonates with the Apgar score $<4$ points in the severe group is larger than that in the mild group $(\mathrm{p}<0.05)$.

Table IV. Correlation of arterial blood gas indexes of patients in the research group with neonate's Apgar score.

\begin{tabular}{lrcccc}
\hline Groups & $\mathrm{n}$ & $\mathrm{pH}$ value & $\begin{array}{c}\text { Neonate's } \\
\text { Apgar score }\end{array}$ & $\mathrm{r}$ & P-value \\
\hline Mild & 216 & $7.34 \pm 0.11$ & $7.59 \pm 1.49$ & 0.346 & $<0.05$ \\
Moderate & 73 & $7.24 \pm 0.13$ & $6.15 \pm 1.13$ & 0.409 & $<0.05$ \\
Severe & 59 & $7.09 \pm 0.29$ & $5.08 \pm 0.91$ & 0.634 & $<0.05$
\end{tabular}

( $\mathrm{p}>0.05)$. No statistically significant differences were found in the comparison of neonate's sex, fetal age and body weight, respectively, between the research and control groups ( $>0.05)$ (Table I).

Blood gas analysis results of research and control groups. In this study, the $\mathrm{pH}$ value, and $\mathrm{PO}_{2}$ and $\mathrm{HCO}_{3}^{-}$levels in mild, moderate and severe patients in the research group were lower than those in the control group $(\mathrm{p}<0.05)$. In the research group, the $\mathrm{pH}$ value, and $\mathrm{PO}_{2}$ and $\mathrm{HCO}_{3}^{-}$levels in mild patients were higher than those in moderate patients $(\mathrm{p}<0.05)$, and they were also higher in moderate patients than those in severe patients $(\mathrm{p}<0.05)$. Moreover, $\mathrm{PCO}_{2}$ and $\mathrm{BE}$ levels in mild, moderate and severe patients in the research group were higher than those in the control group $(\mathrm{p}<0.05)$. In the research group, $\mathrm{PCO}_{2}$ and $\mathrm{BE}$ levels in mild patients were lower than those in moderate patients $(\mathrm{p}<0.05)$, and they were also lower in moderate patients than those in severe patients $(p<0.05)$. With the exacerbation of the patient's disease in the research group, the differences of indexes from normal values became larger (Table II).

Apgar scores of neonates in research and control groups. Apgar scoring was performed for neonates in the research and control groups at 1,5 and 10 min after maternal delivery. The incidence rate of mild asphyxia (Apgar score, 4-6 points) in neonates in the research group was higher than that in the control group $(\mathrm{p}<0.05)$. The incidence rate of severe asphyxia (Apgar score, $<4$ points) in neonates in the research group was also higher than that in the control group $(\mathrm{p}<0.05)$. With the exacerbation of the patient's disease in the research group, the incidence rate of neonatal asphyxia became higher (Table III).

Correlation of arterial blood gas indexes of pregnant women in research group with neonate's Apgar score at 1 min after birth. In the research group, the $\mathrm{pH}$ value of arterial blood of patients was positively correlated with the neonate's Apgar score at 1 min after birth $(\mathrm{p}<0.05)$. With the exacerbation of the patient's disease, the $\mathrm{pH}$ value became increasingly lower than the normal value, and the neonate's Apgar score was also 
reduced (Table IV). There were no correlations of the arterial blood $\mathrm{PO}_{2}, \mathrm{PCO}_{2}, \mathrm{HCO}_{3}{ }^{-}$and $\mathrm{BE}$ with the neonate's Apgar score of patients in the research group ( $\mathrm{p}>0.05)$.

\section{Discussion}

Pregnancy-induced hypertension syndrome is a unique symptom of pregnant women during pregnancy, which often produces adverse effects on pregnant women and fetuses (11). At present, the pathogenesis of pregnancy-induced hypertension syndrome remains unclear. The high-risk groups mainly include the young primipara after pregnancy for 20 weeks, elderly primipara, and pregnant women with hypertension complicated with diabetes mellitus, twins, polyhydramnios and hydatid mole $(12,13)$. Pregnancy-induced hypertension syndrome leads to such clinical symptoms as heart failure, coagulation dysfunction, cerebral hemorrhage, renal failure, blood circulation disorders and placental abruption in pregnant women, as well as premature birth, intrauterine death, stillbirth and neonatal asphyxia, which is one of the main causes of death of pregnant women and perinatal infants $(14,15)$. Therefore, the early judgement of neonatal asphyxia in pregnant women with pregnancy-induced hypertension syndrome is of great significance in early monitoring and intervention of neonates.

Blood gas analysis is to detect the $\mathrm{pH}$ value, $\mathrm{PCO}_{2}, \mathrm{HCO}_{3}{ }^{-}$, and $\mathrm{BE}$, in the blood, and commonly used to determine the presence or absence of hypoxia and acid-base poisoning in the body or determine the degree of hypoxia, which plays an important role in clinical application (16). In this study, the $\mathrm{pH}$ value and $\mathrm{PO}_{2}$ and $\mathrm{HCO}_{3}{ }^{-}$levels in the research group were lower than those in the control group $(\mathrm{p}<0.05)$, while $\mathrm{PCO}_{2}$ and $\mathrm{BE}$ levels in the research group were higher than those in the control group $(\mathrm{p}<0.05)$. With the exacerbation of disease of pregnant women with pregnancy-induced hypertension syndrome, the arterial blood $\mathrm{pH}$ value, $\mathrm{PCO}_{2}$ and $\mathrm{HCO}_{3}{ }^{-}$levels became lower, but $\mathrm{PCO}_{2}$ and $\mathrm{BE}$ levels increased. Therefore, arterial blood gas analysis can reflect the condition of patients with pregnancy-induced hypertension syndrome to a certain degree. It is believed after analysis that in pregnancy-induced hypertension syndrome, the systemic arteriolar spasm, lumen stenosis and increased surrounding resistance cause damage to vascular endothelial cells, leading to systemic hypoxia and ischemia, and acid-base imbalance, thereby resulting in functional disorders of organs in the body and changes in the arterial blood gas analysis indexes of pregnant women $(17,18)$. The Apgar score is used to evaluate the presence or absence of respiratory depression in neonates, and it is simple and applicable, which has always been clinically used as a monitoring index of neonatal asphyxia (19). Results in this study revealed that the incidence rate of neonatal asphyxia in the research group was higher than that in the control group $(p<0.05)$. With the exacerbation of the patient's condition, the incidence rate of neonatal asphyxia became higher. Moreover, the arterial blood $\mathrm{pH}$ of patients in the research group was positively correlated with the neonate's Apgar score at 1 min after birth. With the decline in the $\mathrm{pH}$ value, the neonate's Apgar score became lower and the risk of asphyxia increased. It is believed after analysis that neonatal asphyxia is an emergency condition caused by insufficient oxygen supply in uterus or during delivery, whose essential reason is respiratory and circulatory disturbances due to neonatal hypoxia and acidosis. Hypoxia and acid-base imbalance in patients with pregnancy-induced hypertension syndrome lead to functional disorders of the body, result in decreased blood supply and circulation between mother and fetus, damage the function of placenta, causing intrauterine hypoxia and producing neonatal acidosis and asphyxia during delivery $(20,21)$. According to reports of Wang et al (22), the risk of neonatal asphyxia in pregnant women with pregnancy-induced hypertension is significantly higher than that in normal pregnant women, and it is increased with the exacerbation of the patient's condition, indicating similar results to the results of this study.

In this study, patients with pregnancy-induced hypertension syndrome were screened strictly in accordance with inclusion and exclusion criteria, thus, improving the reliability of the results in this study. Apgar score has always been clinically used as a preferred monitoring index for judging neonatal asphyxia. However, its disadvantage is that it is easily affected by the subjective factors of the scorer when the neonate's score is low, often leading to inaccurate results. Besides, the Apgar score is vulnerable to other neonatal diseases, lacking specificity in the judgement (23). In this study, the changes in blood gas indexes and acid-base balance in patients with pregnancy-induced hypertension syndrome were detected, combined with the neonate's Apgar score, which could make countermeasures against neonatal asphyxia during delivery in advance. There were certain limitations in this study: neonatal asphyxia cannot be accurately judged yet. Therefore, it is hoped that a better way to judge neonatal asphyxia can be found in our next study.

In conclusion, the arterial blood gas and acid-base balance in patients with pregnancy-induced hypertension syndrome may determine the severity of disease to a certain degree, and, in combination with the neonate's Apgar score, help monitoring and intervention of infants to be born, thus, improving the fertility quality.

\section{Acknowledgements}

Not applicable.

\section{Funding}

No funding was received.

\section{Availability of data and materials}

The datasets used and/or analyzed during the present study are available from the corresponding author on reasonable request.

\section{Authors' contributions}

YC and MW drafted the manuscript. YC, MW and YY were mainly devoted to specimen collection. CL and QB analyzed the blood gas indexes. YC, MW and ML were responsible for statistical analysis. All authors read and approved the final manuscript.

\section{Ethics approval and consent to participate}

The study was approved by the Ethics Committee of the First People's Hospital of Jining (Jining, China). Signed informed consents were obtained from the patients or guardians. 


\section{Patient consent for publication}

Not applicable.

\section{Competing interests}

The authors declare that they have no competing interests.

\section{References}

1. Lo JO, Mission JF and Caughey AB: Hypertensive disease of pregnancy and maternal mortality. Curr Opin Obstet Gynecol 25: $124-132,2013$

2. van Middendorp D, ten Asbroek A, Bio FY, Edusei A, Meijjer L, Newton $S$ and Agyemang C: Rural and urban differences in blood pressure and pregnancy-induced hypertension among pregnant women in Ghana. Global Health 9: 59, 2013.

3. Dunietz GL, Strutz KL, Holzman C, Tian Y, Todem D, Bullen BL and Catov JM: Moderately elevated blood pressure during pregnancy and odds of hypertension later in life: The POUCHmoms longitudinal study. BJOG 124: 1606-1613, 2017.

4. Veerbeek JH, Hermes W, Breimer AY, van Rijn BB, Koenen SV, Mol BW, Franx A, de Groot CJ and Koster MP: Cardiovascular disease risk factors after early-onset preeclampsia, late-onset preeclampsia, and pregnancy-induced hypertension. Hypertension 65: 600-606, 2015.

5. Cnattingius S, Norman M, Granath F, Petersson G, Stephansson O and Frisell T: Apgar score components at 5 minutes: Risks and prediction of neonatal mortality. Paediatr Perinat Epidemiol 31: 328-337, 2017.

6. Magee LA, Pels A, Helewa M, Rey E and von Dadelszen P; Canadian Hypertensive Disorders of Pregnancy Working Group: Diagnosis, evaluation, and management of the hypertensive disorders of pregnancy: Executive summary. J Obstet Gynaecol Can 36: 416-441, 2014 (In English, French).

7. Ye C, Ruan Y, Zou L, Li G, Li C, Chen Y, Jia C, Megson IL, Wei J and Zhang W: The 2011 survey on hypertensive disorders of pregnancy (HDP) in China: Prevalence, risk factors, complications, pregnancy and perinatal outcomes. PLoS One 9: e100180, 2014

8. Ferrazzi E, Stampalija T, Monasta L, Di Martino D, Vonck S and Gyselaers W: Maternal hemodynamics: A method to classify hypertensive disorders of pregnancy. Am J Obstet Gynecol 218 124.e1-124.e11, 2018.

9. Siddiqui A, Cuttini M, Wood R, Velebil P, Delnord M, Zile I, Barros H, Gissler M, Hindori-Mohangoo AD, Blondel B, et al; Euro-Peristat Scientific Committee: Can the Apgar score be used for international comparisons of newborn health? Paediatr Perinat Epidemiol 31: 338-345, 2017.
10. Iliodromiti S, Mackay DF, Smith GC, Pell JP and Nelson SM: Apgar score and the risk of cause-specific infant mortality: A population-based cohort study. Lancet 384: 1749-1755, 2014.

11. Rincon MP, Kuo K, Sabol B and Burwick R: Adverse neonata outcomes among women with hypertensive disorders of pregnancy. Obstet Gynecol 129: 37S-38S, 2017.

12. Pourali L, Vatanchi AM and Hamidi A: A case of Cushing's syndrome in pregnancy. Iran J Med Sci 42: 607-610, 2017.

13. Retnakaran R, Qi Y, Connelly PW, Sermer M, Zinman B and Hanley AJ: Glucose intolerance in pregnancy and postpartum risk of metabolic syndrome in young women. J Clin Endocrinol Metab 95: 670-677, 2010.

14. Cabanes L, Chalas C, Christin-Maitre S, Donadille B, Felten ML, Gaxotte V, Jondeau G, Lansac E, Lansac J, Letur H, et al: Turner syndrome and pregnancy: Clinical practice. Recommendations for the management of patients with Turner syndrome before and during pregnancy. Eur J Obstet Gynecol Reprod Biol 152: 18-24, 2010.

15. Palomba S, Falbo A, Russo T, Tolino A, Orio F and Zullo F: Pregnancy in women with polycystic ovary syndrome: The effect of different phenotypes and features on obstetric and neonatal outcomes. Fertil Steril 94: 1805-1811, 2010.

16. Day TK: Blood gas analysis. Vet Clin North Am Small Anim Pract 32: 1031-1048, 2002.

17. Lowe SA, Bowyer L, Lust K, McMahon LP, Morton M, North RA, Paech M and Said JM: SOMANZ guidelines for the management of hypertensive disorders of pregnancy 2014. Aust N Z J Obstet Gynaecol 55: e1-e29, 2015.

18. Duley L, Meher S and Jones L: Drugs for treatment of very high blood pressure during pregnancy. Cochrane Database Syst Rev 7: CD001449, 2013.

19. Svenvik M, Brudin L and Blomberg M: Preterm birth: A prominent risk factor for low Apgar scores. BioMed Res Int 2015: 978079, 2015

20. Xu SZ, Hu XY, Zhao F, Zhou YX and Zhang SC: Effect of pregnancy-induced hypertension syndrome on complications in very low birth weight preterm infants. Zhongguo Dang Dai Er Ke Za Zhi 19: 402-404, 2017 (In Chinese).

21. Kintiraki E, Papakatsika S, Kotronis G, Goulis DG and Kotsis V: Pregnancy-induced hypertension. Hormones (Athens) 14: 211-223, 2015.

22. Wang J, Liu X, Zhu T and Yan C: Analysis of neonatal respiratory distress syndrome among different gestational segments. Int J Clin Exp Med 8: 16273-16279, 2015.

23. Ozdemir AA and Elgormus Y: Diagnostic value of presepsin in detection of early-onset neonatal sepsis. Am J Perinatol 34: 550-556, 2017.

This work is licensed under a Creative Commons Attribution-NonCommercial-NoDerivatives 4.0 International (CC BY-NC-ND 4.0) License. 